\title{
Impact of ablation of Barrett's esophagus with low-grade dysplasia on patients' illness perception and quality of life: a multicenter randomized trial
}

\author{
Wilda D. Rosmolen, MSc, ${ }^{1}$ Nadine K. Y. N. Phoa, PhD, ${ }^{1}$ Phytia T. Nieuwkerk, PhD, ${ }^{2}$ Roos E. \\ Pouw, MD, PhD, ${ }^{1}$ Bas L. A. M. Weusten, MD, PhD, ${ }^{3}$ Raf Bisschops, MD, PhD, ${ }^{4}$ Erik J. Schoon, MD, \\ $\mathrm{PhD}{ }^{5}$ \\ Mirjam A. G. Sprangers, PhD, ${ }^{2}$ Jacques J. G. H. M. Bergman, MD, PhD ${ }^{1}$ \\ Amsterdam, Nieuwegein, The Netherlands; Leuven, Belgium; Eindhoven, The Netherlands
}

\begin{abstract}
Background and Aims: A previous multicenter randomized trial demonstrated that radiofrequency ablation (RFA) significantly reduced the risk of neoplastic progression compared with surveillance $(1.5 \%$ vs $26.5 \%)$ in patients with Barrett's esophagus (BE) and low-grade dysplasia(LGD). In the same population, this study aimed to compare the quality of life (QOL) and illness perception (IP) among patients treated with RFA and patients kept under surveillance.
\end{abstract}

Methods: From June 2007 to June 2011, patients with BE and LGD were randomly assigned to RFA or surveil- lance. QOL and IP were assessed at baseline, 2, 9, 14, 26, and 38 months. Standardized questionnaires were used (SF-36, EORTC QLQ-C30, EORTC QLQ-OES18, and the brief Illness Perception Questionnaire [IPQ]).

Results: Forty-seven patients in the ablation group and 49 patients in the surveillance group completed the question- naires (median follow-up, 36 months). Marginal differences were observed in the SF-36 and the EORTC-QLQ-C30. Based on the EORTC-QLQ-OES18, the ablation group reported more diarrhea (7.8vs 4.0; $P Z$.018), whereas the surveillance group reported more reflux $(15.1 \mathrm{vs} 9.0 ; P<.001)$ and more problems with speaking (4.3 vs $2.2 ; P Z$.019). The IPQ showed that patients in the ablation group perceived their disease lasted for a shorter period of time $(P<.001)$, expe- rienced fewer symptoms $(P<.001)$, had fewer concerns about their condition $(P<.001)$, and tended to be less emotionally affected by their condition $(P Z$.012) than patients in the surveillance group. As a result, patients who underwent ablation experienced their condition as less threatening compared with patients in the surveillance group $(P<.001)$.

Conclusion: Patients treated with ablation for BE with LGD reported a QOL comparable with that of patients undergoing endoscopic surveillance; however, the patients in the ablation group had fewer concerns and a less-threatening view of their condition. (Clinical trial registration number [www.trialregister.nl]: NTR1 198; 25-1-2008.) (Gastrointest Endosc 2019;90:215-21.)

\section{INTRODUCTION}

Most (inter)national guidelines advise that patients with Barrett's esophagus (BE) and confirmed lowgradedysplasia (LGD) should be treated with prophylactic radiofrequency ablation (RFA) instead of keeping patients under endoscopic surveillance. ${ }^{1-3}$ This advice is largely based on the results of 2 landmark studies. The AIM Dysplasia trial randomized pa- tients with high-grade dysplasia (HGD) and LGD to either RFA or sham treatment. For patients with BE and LGD, after 12 months, they found that there was less disease progression from LGD to HGD/cancer in patients treated with RFA (5\%) compared with sham-treated patients (14\%), although this was not significant $\left(P Z\right.$.33). ${ }^{4}$ The SURF study was a randomized trial comparing endoscopic surveillance with prophylactic RFA treatment in patients with BE and confirmed LGD. This study showed that RFA reduced neoplastic progression from $26.5 \%$ to $1.5 \%$ compared with standard endoscopic surveillance. ${ }^{5}$ The trial was closed before all patients reached the projected 36-month follow- up, due to the superiority of RFA in preventing progression to HGD and esophageal adenocarcinoma(EAC).

Compared with surveillance, RFA is an invasive procedure, and in the SURF trial, 3 serious adverse events were observed (4-day admission for pain; postprocedural bleeding; admis- sion and antibiotic treatment for fever after dilation of a stric- ture after RFA). In addition, $12 \%$ of patients developed a stricture after RFA requiring endoscopic dilation. In the sur- veillance group, no adverse events occurred (risk difference, 19.1\%; 
95\% confidence interval $[\mathrm{CI}], 9.7 \%-28.4 \% ; P<.001)$. Given the superiority of RFA in terms of preventing oncologic progression, this risk difference is considered to be acceptable by physicians. However, little is known about perceived health of patients during RFA treatment compared with surveillance. QOLandillness perception (IP) among patients with LGD may be influenced by the known risk of neoplastic progression and the need for regularendoscopic surveillance. QOL dataas re- ported in the AIM Dysplasia Trial suggested that patients with $\mathrm{BE}$ and LGD and HGD who were randomized to RFA instead of sham experienced an improvement in disease-specific health-related QOL. ${ }^{6}$ This improvement seemed to be secondary to a perceived decrease in the risk of developing cancer. ${ }^{6}$ We hypothesized that ablation of confirmed LGD may have a negative short-term physical impact but improves long-term QOL and alleviates the fear and threat of the disease in a positive manner compared with standard endoscopic sur- veillance. As part of the randomized SURF-trial, we present QOL and IP among patients with confirmed LGD, comparing surveillance andablation. ${ }^{5}$

\section{METHODS}

\section{Study design and patients}

Patients were enrolled in the SURF trial between June 2007 and June 2011 in 9 centers from 5 European countries. ${ }^{5}$ In addition, QOL and IP was measured in the same patients. The Institutional Review Board of each center approved the study protocol (NTR1 198; 25-1-2008; www.trialregister.nl). All authors had access to the study data and reviewed and approved the final manuscript. Patients with a histologically confirmed diagnosis of LGD and BE were randomly assigned in a 1:1 ratio to either RFA or endoscopic surveillance. Details of the RFA treatment and endoscopic surveillance have been described in detail elsewhere. ${ }^{5}$ After written informed consent was obtained from all eligible patients in the 3 Dutch centers and 1 Belgian center, questionnaires on QOL and IP were mailed to the patients' home at baseline (before randomization) and at 2, 9, 14, 26, and 38 months after randomization. The time intervals of the assessments were selected to avoid direct influence of endoscopy and/or treatment on QOL and IP (Fig. 1). After 2 weeks, a reminder including the same set of questionnaires was sent, if necessary.

\section{Ablation group}

Patients assigned to the ablation group were treated with RFA. ${ }^{7,8}$ Subsequent ablation sessions were performed every 3 months until complete endoscopic and histologic eradication of all Barrett's mucosa was reached, with a maximum of 2 circumferential and 3 focal ablation ses- sions. Subsequent follow-up endoscopies were performed annually thereafter until 3 years after randomization (2 years after completion of ablation).

\section{Surveillance group}

Patients assigned to the surveillance group underwent high-resolution endoscopy at 6 and 12 months after the baseline endoscopy, and annually thereafter until 3 years after randomization. At each follow-up endoscopy, 4- quadrant biopsy specimens were obtained from every $2 \mathrm{~cm}$ of Barrett's epithelium. If histology showed either LGD or no dysplasia, patients were scheduled for follow- up according to the study protocol. If post-randomization biopsy samples showed HGD or EAC, patients were treated endoscopically or surgically.

\section{Quality of life}

QOL was measured by 3 well-validated and widely used questionnaires. The SF-36 measures generic quality of life. Its 36 items are combined to form 8 subscales: physical functioning, social functioning, physical role functioning, emotional role functioning, vitality, bodily pain, mental health, and general health. ${ }^{9,10}$

The EORTC-QLQ-C30 is a cancer-specific questionnaire with 30 items, divided into 5 functional scales (physical functioning, emotional functioning, cognitive functioning, social functioning, and role functioning); 3 symptom scales (fatigue, pain, nausea and vomiting), and 5 individual symptoms (shortness of breath, insomnia, appetite loss, constipation, and diarrhea). ${ }^{11,12}$ The raw scores of these QOL questionnaires were converted linearly to a 0 to 100 scale. A higher score in the functional scales on the SF- 36 and the EORTC-QLQ-C30 indicated better QOL. ${ }^{9-12}$

The EORTC-QLQ-OES18 was used to measure esopha- geal cancer-specific QOL. This 18-item questionnaire mea- sures 10 esophageal cancer-specific symptoms: dysphagia, reflux, pain, eating problems, trouble speaking, coughing, trouble swallowing, choking, dry mouth, and taste. ${ }^{13}$ 
The raw scores were also converted linearly to a 0 to 100 scale; higher scores on the symptom scales indicated more symptoms. ${ }^{11-13}$

\section{Illness perception}

IP was measured by the brief Illness Perception Ques- tionnaire (IPQ), a 9-item questionnaire designed to assess cognitive and emotional representations of illness. Each of the items holds a perception about one aspect of the illness, and together they provide the individual's view of an illness. The items are (1) consequences on life; (2) time- line: duration of the illness; (3) personal control of the illness; (4) treatment control of the illness; (5) symptoms experienced; (6) concerns about the illness; (7) understanding the illness; (8) emotional representation of the illness. The response options range from "certainly not"

(0) to "certainly" (10). After conversion of 3 items, an over- all score can be computed, provided that the internal con- sistency is above 0.6. A higher overall score (maximum 80 ) indicates that the illness is being perceived as more fearful and threatening. ${ }^{14-16}$

\section{Statistical analysis}

SPSS (IBM version 20.0) was used for the statistical an- alyses. Demographic characteristics and clinical data were compared at baseline using independent samples $t$ tests forcontinuous data. Categoricaldata were compared using the chi-squared or Fisher exact test where appropriate.

We investigated differences between the ablation and surveillance group in mean quality of life and IPs across all time points after randomization adjusted for the base- line measurement using mixed linear models. Mixed linear models can handle missing measurements without the need for imputation. Because we conducted multiple sta- tistical tests, significant results could arise due to chance (type I error). Therefore, we applied a Bonferroni correc- tion to the conventional critical $P$ value of .05 by dividing this value by the number of statistical tests conducted, which resulted in a value of $.0012 .{ }^{17,18}$ Two-sided $P$ values $<.0012$ were considered to indicate statistical signif- icance. Although the Bonferroni correction protects from type I error, it is vulnerable to type II errors (failing to reject the null hypothesis when the null hypothesis should in fact be rejected). We therefore consider the uncorrected critical $P$ value of .05 to represent a trend.

\section{RESULTS}

For this study, 511 patients were screened, of whom 136 were found to be eligible and were randomized to RFA or surveillance. In 3 Dutch centers and 1 Belgian center, 111 patients participated in the study. ${ }^{5}$ The first 5 patients randomized in the Dutch and Belgian centers were not included in this QOL IP study. Four other patients did not consent to completing the questionnaires, and 6 patients were excluded because of other life-threatening co-morbidities. In total, 96 patients ( 47 patients in the ablation group and 49 patients in the surveillance group) enrolled in the QOL IPQ part of the study. All patients completed the baseline measurement. The response rate of the follow-up measurements varied between $95.8 \%$ and $98.9 \%$. The trial closed on May 8, 2013. At that time, all patients were followed for at least 24 months, with a me- dian follow-up of 36 months (interquartile range, 30-36 months). There were no statistically significant differences between the 2 study groups in demographic and clinical characteristics at baseline $(P>.10)$ (Table 1).

Fifteen patients in the surveillance group $(15 / 49 ; 30.6 \%)$ included in this analysis progressed from LGD to HGD (n Z9) or EAC (n Z 6); in the ablation group, 1 patient $(1 / 47 ; 2.1 \%)$ showed progression to EAC $(P<.001)$. Four- teen patients with progression could be treated endoscop- ically. One patient with poorly differentiated submucosal adenocarcinoma underwent esophagectomy.

\section{Quality-of-life functional scales}

Patients in the surveillance group tended to have higher scores on the SF-36 physical functioning scale, indicating better functioning than patients in the ablation group (80.4 vs $77.3 ; P \mathbf{Z}$.038) (Table 2). Patients in the ablation group tended to have higher scores on the EORTC-QLQ-C30 cognitive functioning scale, indicating better cognitive functioning, than patients in the surveil- lance group (86.6 vs 83.0; $P Z \mathbf{Z}$.028) (Table 2). No significant changes from baseline to 38 months after treatment were found on the SF-36 and the functional scales of the EORTC-QLQ-30. 


\section{Quality-of-life symptom scales}

On a scale from 0 to 100 , the ablation group tended to report more diarrhea ( $7.8 \mathrm{vs} 4.0 ; P Z$.018), but the surveil- lance group reported more reflux $(15.1$ vs $9.0 ; P<.001)$ and more problems with speaking (4.3 vs 2.2; PZ.019) (Table 3). No significant changes from baseline to 38 months after treatment were found on the symptom scales of the EORTC-QLQ-30 and the EORTC-QLQ-OES18.

\section{Illness perception}

Our analyses showed that in 6 of the 9 items of the Illness Perception Scale, there was not only a significant overall group effect but also a significant time effect. There- fore, we decided to show the results at baseline, 14, 26, and 38 months in Table 4 . From 14 months after baseline, the patients in the ablation group perceived their disease to be lasting for a significantly shorter period of time $P<.001)$, experienced fewer symptoms ( $P Z$.002), had fewer concerns about their illness $(P<$

$.001)$, and were less emotionally affected by their illness $(P<.001)$ than patients in the surveillance group. As a result, patients in the ablation group experienced their disease as less threatening compared with patients in the surveillance group $(P<.001)$ (Table 4$)$.

\section{DISCUSSION}

The role of RFA for patients with confirmed LGD in BE was investigated in the SURF trial, arandomized controlled trial comparing RFA with endoscopic surveillance. In addi- tion, we investigated QOL and IP.

In both groups, the progression to HGD and EAC was as- sessed. The study showed that neoplastic progression was significantly lower (1.5\%) in the ablation arm compared with the surveillance arm (26.5\%). ${ }^{5}$ In our randomized trial of RFA versus endoscopic surveillance among patients with confirmed LGD in BE, we found that patients assigned to RFA perceived their condition to be significantly less threatening than patients assigned to endoscopic surveillance. Specifically, patients assigned to RFA perceived their condition to be more under control, perceived fewer symptoms, had fewer concerns about their condition, and perceived fewer emotional consequences than patients assigned to endoscopic surveillance. In addition, patients assigned to ablation reported better cognitive functioning, less reflux, and fewer problems with speaking, but reported worse physical functioning and more diarrhea than patients assigned to surveillance.

Our hypothesis that ablation of confirmed LGD may have negative short-term physical impact was confirmed with the SF-36 physical functioning subscale. Although the symptoms were not systematically studied, most patients report pain, dysphagia, and physical unwell-being to some extentin the

1 to 2 weeks after ablation. ${ }^{19}$ This may explain the significant negative impact on physical functioning for the ablation group on SF-36.

Reflux, problems with speaking, and diarrhea were the only symptoms that occurred with a significant difference between the ablation group and the surveillance group. This may be explained by the strict treatment protocol pre- scribing additional acid-suppressing medication for 2 weeks after each treatment session with maintenance pro- ton pump inhibitor (PPI) therapy. Furthermore, multiple patient-physician contact moments before and after each treatment session stressing the importance of PPI therapy may have increased compliance in the ablation group compared with the surveillance group. Reflux was reported more often in the surveillance group, and this may have re- sulted in more problems with speaking. If patients in the ablation group were indeed more compliant in using the prescribed PPIs as mentioned above, this may explain the higher rate of patients reporting diarrhea, a common side effect of PPI therapy.

The most important finding in our study was that patients randomized to ablation had less concerns and perceived their condition to be less threatening than patients in the surveillance group. Patients in the ablation group perceived their disease as lasting for a significantly shorter period of time, experienced fewer symptoms, had fewer concerns about their condition, and were less emotionally affected by their condition than patients in the surveillance group. Because we used the intention-to-treat principle to analyze the data, one may question whether the patients who pro- gressed to HGD/cancer in the surveillance group may have been responsible for the observed difference in IP. Yet after excluding the patients who progressed from the surveillance group, the results remained statistically significant. This suggests that IP in patients with LGD is influenced positively by ablation treatment.

Our analyses showed that in 6 of the 9 items of the Illness Perception Scale, there was not only 
significant overall group effect but also a significant time effect. After 14 months, the ablation group had a more positive IP than the surveillance group. The positive effect of ablation on IP in patients with LGD persists over time. This suggests again that IP was influenced by the treatment to which pa- tients were assigned.

The strengths of this study are the randomized controlled design, a follow-up of 36 months, a response rate of $97.4 \%$, and the use of standardized well-validated questionnaires. The limitations of this study include the use of a cancer- and tumor-specific questionnaire (the EORTC-QLQ-C30 and the EORTC-QLQ-OES18) in patients with a premalignant condition. ${ }^{20}$ However, the symptoms measured in the EORTC-QLQ-OES18 cover all symptoms that can occur after any treatment for (early) esophageal neoplasia, and RFA is applied in the same manner for pa- tients with BE and LGD as for patients who previously un- derwent endoscopic resection for early cancer. ${ }^{20}$

There were subtle differences in QOL and IP between the groups at baseline despite randomization. One of the items in the IPQ, personal control of the illness, was significantly different at baseline between the 2 groups. We controlled for these a priori differences by including the baseline mea- surements as covariates. Third, the number of statistical tests performed can induce chance effects. Although most significant differences occurred on the same instrument, ie, the IPQ, and were in the same direction, to avoid the risk of chance we applied a Bonferronicorrection to the con- ventional critical $P$ value of .05 and considered the uncorrec- ted critical $P$ value of .05 to represent a trend.

The results in QOL outcomes of this randomized study are comparable with the results of a prospective study investigating QOL in patients with early neoplasia, in which no significant differences in healthrelated QOL were re- ported between patients undergoing surveillance for non- dysplastic BE and patients treated endoscopically for early Barrett's neoplasia. ${ }^{4}$ Any differences in QOL that may occur after less-invasive treatment may not be detected by general health-related QOL instruments such as the SF-36 and the functional scales of the EORTC-QLQ-C30. Howev- er, disease-related symptoms and the impact of possible progression toward carcinoma on well-being and IP can be detected by specific questionnaires such as the EORTC-QLQ-OES18 and the IPQ.

The AIM Dysplasia Trial, however, showed that patients treated with RFA for dysplastic BE had a better QOL compared with patients who had a sham procedure. QOL, however, was measured with a self-made question- naire in which general health-related QOL was combined with worry for cancer and IP, not a standardized and vali- dated questionnaire. Our results regarding concerns about the illness, the emotional impact, and the threat of the illness are similar to the results for the AIM Dysplasia Trial.4 The SURF trial showed that RFA in patients with BE and a confirmed diagnosis of LGD reduced the risk of pro- gression to HGD or EAC from $26.5 \%$ to $1.5 \%(\mathrm{P}<.001)$, an absolute risk reduction of $25.0 \%$ (95\% CI, 14.1-35.9). 5 In this study, we found that ablation was not associated with significant differences in QOL compared with surveil- lance. Ablation, however, was associated with fewer con- cerns and a less-threatening view of illness compared with endoscopic surveillance. Our results strengthen the recommendation to treat selected patients with confirmed

LGD and BE with RFA.5

\section{ACKNOWLEDGMENTS}

This investigator-initiated trial was supported, in part, by Covidien GI Solutions (formerly BÂRRX Medical) and by the Maag Lever Darm Stichting grant WO 07-60 from the Dutch Digestive Diseases Foundation. Covidien GI Solu- tions provided ablation devices and access to a central elec- tronic data management system.

\section{REFERENCES}

1. Shaheen NJ, Falk GW, lyer PG, et al. ACG clinical guideline: diagnosis and management of Barrett's esophagus. Am J Gastroenterol 2016;111:30-50; quiz 51.

2. di Pietro M, Fitzgerald RC. Revised British Society of Gastroenterology recommendation on the diagnosis and management of Barrett's oesophagus with low-grade dysplasia. Gut 2018;67:392-3.

3. Weusten B, Bisschops R, Coron E, etal. Endoscopic management of Barrett's esophagus: European Society of Gastrointestinal Endoscopy (ESGE) Position Statement. Endoscopy 2017;49:191-8

4. Shaheen NJ, Sharma P, Overholt BF, et al. Radiofrequency ablation in Barrett's esophagus with dysplasia. N Engl J Med 2009;360:2277-88. 
5. Phoa KN, van Vilsteren FG, Weusten BL, et al. Radiofrequency ablation vs endoscopic surveillance for patients with Barrett esophagus and low- grade dysplasia: a randomized clinical trial. JAMA 2014;311:1209-17.

6. Shaheen NJ, Peery AF, Hawes RH, etal. Quality of life following radio- frequency ablation of dysplastic Barrett's esophagus. Endoscopy 2010;42:790-9.

7. Gondrie JJ, Pouw RE, Sondermeijer CM, et al. Stepwise circumferential and focal ablation of Barrett's esophagus with high-grade dysplasia: re- sults of the first prospective series of 11 patients. Endoscopy 2008;40: 359-69.

8. Gondrie JJ, Pouw RE, Sondermeijer CM, et al. Effective treatment of early Barrett's neoplasia with stepwise circumferential and focal abla- tion using the HALO system. Endoscopy 2008;40:370-9.

9. McHorney CA, Ware JE Jr, Raczek AE. The MOS 36-Item Short-Form Health Survey (SF-36): II. Psychometric and clinical tests of validity in measuring physical and mental health constructs. Med Care 1993;31: 247-63.

10. Ware JE Jr, Gandek B, Kosinski M, et al. The equivalence of SF-36 sum- mary health scores estimated using standard and country-specific al- gorithms in 10 countries: results from the IQOLA Project. International Quality of Life Assessment. J Clin Epidemiol 1998;51: 1167-70.

11. Aaronson NK, Ahmedzai S, Bergman B, et al. The European Organiza- tion for Research and Treatment of Cancer QLQ-C30: a quality-of-life instrument for use in international clinical trials in oncology. J Natl

12. Osoba D, Aaronson N, Zee B, et al. Modification of the EORTC QLQ-C30 (version 2.0) based on content validity and reliability testing in large samples of patients with cancer. The Study Group on Quality of Life of the EORTC and the Symptom Control and Quality of Life Commit- tees of the NCl of Canada Clinical Trials Group. Qual Life Res 1997;6: 103-8.

13. Blazeby JM, Alderson D, Winstone K, et al. Development of an EORTC questionnaire module to be used in quality of life assessment for pa- tients with oesophageal cancer. The EORTC Quality of Life Study Group. Eur J Cancer 1996;32A:1912-7

14. Broadbent E, Petrie KJ, Main J, et al. The brief illness perception ques- tionnaire. J Psychosom Res 2006:60:631-7.

15. Weinman J, Petrie KJ. Illness perceptions: a new paradigm for psycho- somatics? J Psychosom Res 1997:42:113-6.

16. Weinman J, Petrie KJ, Moss-Morris R, et al. The illness perception ques- tionnaire: a new method for assessing the cognitive representation of illness. Psychol Health 1996;11:431-46.

17. Bonferroni CE. II calcolo delle assicurazioni su gruppi di teste. In: Studi in Onore del Professore Salvatore Ortu Carboni [in Italian]. Rome:Ti- pografia del Senato; 1935. p. 13-60.

18. Bonferroni CE. Teoria statistica delle classi e calcolo delle probabilità. Volume 8 [in Italian]. Firenze Pubblicazioni del R Istituto Superiore di Scienze Economiche e Commerciali di Firenze. Florence: Libreria Inter- nazionale Seeber; 1936:3-62.

19. van Munster SN, Overwater A, Haidry R, et al. Focal cryoballoon versus radiofrequency ablation of dysplastic Barrett's esophagus: impact on treatment response and postprocedural pain. Gastrointest Endosc 2018;88:795-803.e2.

20. Rosmolen WD, Nieuwkerk PT, Pouw RE, et al. Quality of life and fear of cancer recurrence after endoscopic treatment for early Barrett's neoplasia: a prospective study. Dis Esophagus 2017;30:1-9

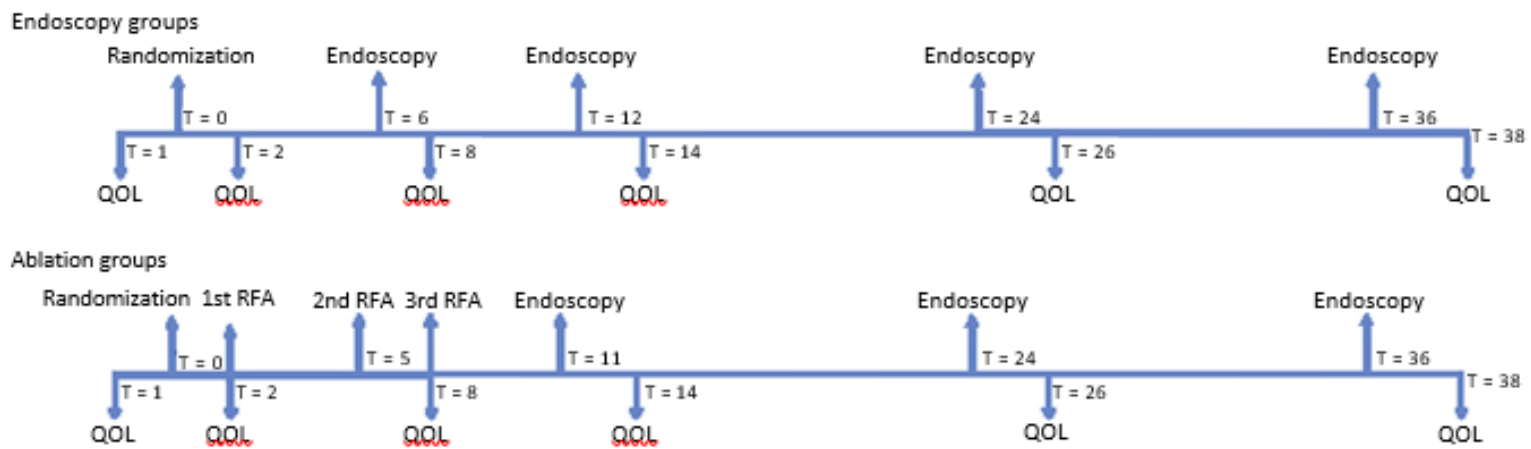

Figure 1. Timeline of quality of life assessment in the surveillance group and ablation group. RFA, Radiofrequency ablation. 
TABLE 1. Demographic and clinical characteristics at baseline

\begin{tabular}{|c|c|c|}
\hline Characteristics & $\begin{array}{l}\text { Surveillance } \\
\text { (n [ } 49 \text { ) }\end{array}$ & $\begin{array}{l}\text { Ablation } \\
\text { (n [47) }\end{array}$ \\
\hline Age (years), mean \pm SD & $61 \pm 8$ & $62 \pm 11$ \\
\hline Male sex, n (\%) & $45(92)$ & $39(83)$ \\
\hline $\begin{array}{l}\text { Circumferential Barrett's esophagus } \\
\text { (cm), median (IQR) }\end{array}$ & $2(1-4)$ & $1(0-4)$ \\
\hline $\begin{array}{l}\text { Maximum Barrett's esophagus (cm), } \\
\text { median (IQR) }\end{array}$ & $4(3-6)$ & $3(2-6)$ \\
\hline $\begin{array}{l}\text { Time since diagnosis of } \mathrm{BE} \text { (years), } \\
\text { median (IQR) }\end{array}$ & $8(4-11)$ & $4(2-11)$ \\
\hline $\begin{array}{l}\text { Time since diagnosis of dysplasia } \\
\text { (years), median (IQR) }\end{array}$ & $2(2-8)$ & $2(2-8)$ \\
\hline $\begin{array}{l}\text { Use of proton pump inhibitors (years), } \\
\text { median (IQR) }\end{array}$ & $10(4-14)$ & $7(5-14)$ \\
\hline Number of comorbidities, median (IQR) & $1(1-2)$ & $1(1-2)$ \\
\hline
\end{tabular}

TABLE 2. Mean quality of life in the ablation group versus the surveillance group across time points after randomization adjusted for the baseline measurement

\begin{tabular}{llcc}
\hline & $\begin{array}{c}\text { Surveillance: estimated } \\
\text { means }(95 \% \mathrm{Cl})\end{array}$ & $\begin{array}{c}\text { Ablation: estimated } \\
\text { means }(95 \% \mathrm{Cl})\end{array}$ & $\begin{array}{c}\text { P value group } \\
\text { effect }\end{array}$ \\
SF-36 & $80.4(78.3-82.6)$ & $77.3(75.1-79.4)$ & $.038^{*}$ \\
\hline Physical functioning & $86.7(84.1-89.3)$ & $85.1(82.4-87.7)$ & .38 \\
\hline Social functioning & $77.8(74.8-83.5)$ & $85.1(73.6-82.0)$ & .66 \\
\hline Role functioning (physical) & $80.3(77.9-82.8)$ & $79.1(76.6-81.6)$ & .49 \\
\hline Bodily pain & $70.5(68.1-72.8)$ & $68.5(66.0-71.0)$ & .25 \\
\hline Vitality & $85.7(81.5-89.9)$ & $81.8(77.6-86.1)$ & .20 \\
\hline Role functioning (emotional) & $81.5(79.3-83.6)$ & $79.4(77.2-81.2)$ & .20 \\
\hline Mental health & $64.1(62.0-66.2)$ & $65.3(63.1-67.6)$ & .44 \\
\hline General health perception & & $87.3(85.8-88.8)$ & .46 \\
\hline EORTC-QLQ-C30 & $88.1(86.6-89.5)$ & $87.3(84.4-90.1)$ & $.028^{*}$ \\
\hline Physical functioning & $85.6(82.8-88.3)$ & $86.6(84.3-88.8)$ & .27 \\
\hline Role functioning & $83.0(80.9-85.2)$ & $92.4(90.1-94.8)$ & .59 \\
\hline Cognitive functioning & $90.6(88.4-92.9)$ & $85.1(82.7-87.6)$ & .57 \\
\hline Social functioning & $84.2(81.9-86.6)$ & $74.7(63.1-67.6)$ & \\
\hline Emotional functioning & $73.9(62.0-66.2)$ & & \\
\hline General health status & & & \\
\hline
\end{tabular}

Cl, Confidence interval.

$* p<.05$. 
TABLE 3. Mean scores for symptom scales in the ablation group versus the surveillance group across time points after randomization adjusted for the baseline measurement

\begin{tabular}{|c|c|c|c|}
\hline & $\begin{array}{l}\text { Surveillance: estimated } \\
\text { means }(95 \% \mathrm{Cl})\end{array}$ & $\begin{array}{l}\text { Ablation: estimated } \\
\text { means }(95 \% \mathrm{Cl})\end{array}$ & $\begin{array}{c}\text { P value group } \\
\text { effect }\end{array}$ \\
\hline \multicolumn{4}{|c|}{ EORTC-QLQ-C30 symptom scales } \\
\hline Fatigue & $22.0(19.6-24.4)$ & $23.5(20.9-26.0)$ & .41 \\
\hline Pain & $16.7(14.2-19.2)$ & $17.7(15.1-20.3)$ & .61 \\
\hline Nausea and vomiting & $4.0(2.6-5.4)$ & $5.6(4.1-7.1)$ & .12 \\
\hline Shortness of breath & $17.8(14.8-20.8)$ & $18.3(15.4-21.1)$ & .80 \\
\hline Insomnia & $19.8(16.6-23.0)$ & $18.7(15.4-22.0)$ & .65 \\
\hline Loss of appetite & $6.5(4.1-8.8)$ & $9.2(6.7-11.6)$ & .12 \\
\hline Constipation & $9.7(7.4-12.1)$ & $12.7(10.3-15.1)$ & .08 \\
\hline Diarrhea & $4.0(1.7-6.2)$ & $7.8(5.5-10.1)$ & $.018^{+}$ \\
\hline Financial problems & $4.5(2.5-6.4)$ & $5.9(3.9-7.9)$ & .30 \\
\hline \multicolumn{4}{|l|}{ EORTC-QLQ-OES18 } \\
\hline Dysphagia & $8.2(6.6-10.9)$ & $6.2(4.0-8.4)$ & .10 \\
\hline Reflux & $15.1(12.9-17.4)$ & $9.0(6.7-11.3)$ & $.000 y$ \\
\hline Pain & $9.6(7.8-11.5)$ & $10.0(8.1-11.9)$ & .79 \\
\hline Eating problems & $10.2(8.0-12.4)$ & $9.1(6.8-11.3)$ & .48 \\
\hline Dry mouth & $19.8(16.4-23.2)$ & $18.9(15.4-22.3)$ & .69 \\
\hline Speaking problems & $4.3(3.1-5.5)$ & $2.2(0.9-3.5)$ & $.02^{*}$ \\
\hline Coughing & $18.5(15.3-21.7)$ & $14.9(11.7-18.1)$ & .11 \\
\hline Trouble swallowing & $8.4(5.8-11.1)$ & $5.5(2.8-8.2)$ & .12 \\
\hline Choking & $6.1(4.1-8.2)$ & $5.2(3.1-7.3)$ & .52 \\
\hline Taste & $6.2(3.8-8.6)$ & $7.0(4.5-9.5)$ & .66 \\
\hline
\end{tabular}

C, Confidence interval.

$* p<.05$.

$\mathrm{X}$ v values $<.0012$ were considered to indicate statistical significance after Bguferroui correction.

TABLE 4. The Illness Perception Questionnaire at baseline, 14, 26, and 38 months

\begin{tabular}{|c|c|c|c|c|c|c|c|c|c|}
\hline \multirow[b]{2}{*}{$\begin{array}{l}\text { Illness Perception } \\
\text { Questionnaire }\end{array}$} & \multicolumn{2}{|c|}{ Baseline mean scores } & \multicolumn{2}{|c|}{$\begin{array}{l}14 \text { months: mean change } \\
\text { from baseline }(95 \% \mathrm{Cl})\end{array}$} & \multicolumn{2}{|c|}{$\begin{array}{l}26 \text { months: mean change } \\
\text { from baseline }(95 \% \mathrm{Cl})\end{array}$} & \multicolumn{2}{|c|}{$\begin{array}{l}38 \text { months: mean change } \\
\text { from baseline }(95 \% \mathrm{Cl})\end{array}$} & \multirow[b]{2}{*}{$\begin{array}{c}P \\
\text { value }\end{array}$} \\
\hline & $\begin{array}{l}\text { Surveillance } \\
\text { (n โ 49) }\end{array}$ & $\begin{array}{l}\text { Ablation } \\
\text { (n [47) }\end{array}$ & $\begin{array}{l}\text { Surveillance } \\
\text { (n [ 49) }\end{array}$ & $\begin{array}{l}\text { Ablation } \\
\text { (n [47) }\end{array}$ & $\begin{array}{l}\text { Surveillance } \\
\text { (n โ 49) }\end{array}$ & $\begin{array}{l}\text { Ablation } \\
\text { (n [ 47) }\end{array}$ & $\begin{array}{l}\text { Surveillance } \\
\text { (n โ 49) }\end{array}$ & $\begin{array}{l}\text { Ablation } \\
\text { (n [47) }\end{array}$ & \\
\hline Overall score & 34.4 & 36.1 & $0.3[1.5]$ & $-8.1(1.6)$ & $-1.4(1.6)$ & $-9.8(1.6)$ & $-1.7[1.9]$ & $-10.1(1.9)$ & $.000 y$ \\
\hline Consequences on life & 4.6 & 4.7 & $-0.1[0.4]$ & $-1.0(0.4)$ & $-0.5[-0.4)$ & $-0.8(0.4)$ & $-0.7(0.4)$ & $-1.0(0.4)$ & .43 \\
\hline $\begin{array}{l}\text { Timeline (duration of } \\
\text { the illness) }\end{array}$ & 6.9 & 7.1 & $1.1(0.4)$ & $-1.2(0.4)$ & $1.1(0.4)$ & $-1.1(0.4)$ & $0.9(0.5)$ & $-1.3(-0.5)$ & $.000 y$ \\
\hline $\begin{array}{l}\text { Personal control of the } \\
\text { illness }\end{array}$ & 5.4 & 6.6 & $0.7(0.4)$ & $-2.2(0.4)$ & $-0.4(0.4)$ & $-1.9(0.4)$ & $-0.3(0.4)$ & $-1.8(0.4)$ & $.000 y$ \\
\hline $\begin{array}{l}\text { Treatment control of the } \\
\text { illness }\end{array}$ & 2.1 & 2.0 & $0.6(0.2)$ & $-0.7(0.3)$ & $0.2(0.30)$ & $-1.2(0.3)$ & $0.2(0.3)$ & $-1.1(0.3)$ & $.000 y$ \\
\hline $\begin{array}{l}\text { Identity (experienced } \\
\text { symptoms) }\end{array}$ & 3.0 & 3.6 & $0.6(0.4)$ & $-0.7(0.4)$ & $0.3(0.4)$ & $-1.0(0.4)$ & $0.0(0.4)$ & $-1.3(0.5)$ & $.002^{\circ}$ \\
\hline IIIness concern & 5.8 & 6.3 & $-0.8[0.4]$ & $-2.2(0.4)$ & $-1.0(0.4)$ & $-2.4(0.4)$ & $-1.2(0.4)$ & $-2.7(0.4)$ & $.000 y$ \\
\hline $\begin{array}{l}\text { Coherence } \\
\text { (understanding the } \\
\text { illness) }\end{array}$ & 2.6 & 2.2 & $0.0(0.3)$ & $-0.1(0.3)$ & $0.0(0.3)$ & $-0.1(0.3)$ & $0.0(0.3)$ & $0.1(0.3)$ & .75 \\
\hline $\begin{array}{l}\text { Emotional } \\
\text { representation }\end{array}$ & 4.0 & 3.8 & $-0.5[0.4)$ & $-1.0(0.4)$ & $-0.8(0.4)$ & $-1.3(0.4)$ & $-0.9(0.4)$ & $-1.4(0.4)$ & .18 \\
\hline
\end{tabular}

